\title{
SUNTINGAN DAN ANALISIS ISI TEKS AKSARA ULU DALAM KOLEKSI PETI 91/E6
}

\author{
Nur Anida ${ }^{1}$, Nyimas Umi Kalsum ${ }^{2}$, Otoman ${ }^{3}$ \\ ${ }^{123}$ Program Studi SPI Fakultas Adab dan Humaniora UIN Raden Fatah. \\ Gmail: nuranida49@gmail.com
}

\begin{abstract}
Abstrak
Skripsi ini berjudul "Suntingan Teks dan Analisis Isi Teks Dalam Koleksi PNRI Peti 91/E6" merupakan naskah melayu yang bertulis aksara Ulu menggunakan dialeg regional. Adapun inti dari rumusan masalah dalam skripsi ini: (1) Bagaimana kajian filologis pada Naskah Aksara Ulu dalam Koleksi PNRI Peti No. 91/E6 (2) Apa isi kandungan Naskah Aksara Ulu dalam Koleksi PNRI Peti No. 91/E6. Penelitian ini menggunakan metode penelitian kualitatif dilakukan secara observasi langsung data primer yang didapatkan dari Gedung PNRI di lantai 9 pada Layanan Koleksi Naskahnaskah Nusantara dengan melakukan dokumentasi pada penemuan data yang terdapat di dalam buku Katalog Induk Naskah-naskah Nusantara Jilid 4 yang diterbitkan oleh Yayasan Obor Indonesia tahun 1998 pada halaman 385, bagian Katalog Naskah Melayu. Kemudian di buku Pendukungan Cagar Budaya Manuskrip Surat Ulu Sumatera Selatan yang diterbitkan oleh Pemerintah Provinsi Sumatera Selatan Dinas Kebudayaan dan Pariwista di halaman 22. Dalam penelitian naskah peneliti menggunakan pendekatan ilmu filologi, yaitu dengan Inventarisasi Naskah, Deskripsi Naskah, Penyalinan Naskah, Suntingan Teks, dan Analisis Teks pada Naskah. Naskah koleksi dengan Nomor Peti 91/E6 merupakan naskah tunggal berbahan bambu berwarna cokelat yang berjumlah 20 bilah, dengan kondisi yang masih bisa terbaca. Teks naskah tersebut mengandung folklor yang berisi tentang Kumbang yang sedang mencari Kuntum Bunga. Adapun gagasan yang disampaikan pada naskah ini ialah suatu hukum mengenai syarat dalam mencari jodoh melalui perantara Rasulullah dan Priayi. Penyampaian ajaran tersebut dengan cara bersyair seperti dilagukan dalam pembacaannya. Hal ini membuktikan kehidupan budaya zaman dahulu mempunyai ajaran agama.

Kata Kunci : Naskah, Akara Ulu, Filologi, Bambu,Teks.
\end{abstract}

\begin{abstract}
This thesis entitled "Editing.Teks.dan.Analisis.Isi.Teks in PNRI Collection Peti 91/E6" is a Malay script written in Ulu script using regional dialect. The essence of the formulation of the problem in this thesis: (1) How is the philological study of the Ulu Script in the Collection of PNRI Peti No. 91/E6 (2) What is the content of the Ulu script in the PNRI Collection Peti No. 91/E6. This study uses a qualitative research method carried out by direct observation of primary data obtained from the PNRI Building on the 9th floor on the Nusantara Manuscripts Collection Service by documenting the discovery of data contained in the Book of the Archipelago Manuscripts Master Catalog Volume 4 published by the Foundation. Indonesia Torch 1998 on page 385, section of the Malay Manuscript Catalog. Then in the book Supporting the Cultural Heritage of the South Sumatra Ulu Manuscript published by the South Sumatra Provincial Government, the Culture and Tourism Office on page 22. In the research paper, the researcher uses a philological approach, namely with Manuscript Inventory, Manuscript Description, Manuscript Copying, Text Editing, and Text Analysis on Manuscripts. The collection manuscript with Case Number 91/E6 is a single manuscript made of brown bamboo, totaling 20 blades, in a legible condition. The text of the manuscript contains a folklore about a beetle looking for a flower bud. The idea presented in this manuscript is a law regarding the requirements for finding a mate through the intermediary of the Prophet and Priyayi. The teaching is conveyed by means of poetry as if it is sung in the reading. This proves that ancient cultural life had religious teachings.
\end{abstract}

Keywords: Manuscript, Akara Ulu, Philology, Bamboo, Text. 
Tanjak: Jurnal Sejarah dan Peradaban Islam, Vol. I No. 2, 2021

\section{A. PENDAHULUAN}

Perkembangan prasasti di Indonesia terjadi pada abad ke-8 hingga abad ke-14. Prasasti tertua ditemukan di Indonesia pada aba ke-5 berupa Prasasti Yupa dari Kerajaan Kutai , di pulau Sumatera sendiri juga mempunyai bukti peninggalan prasasti dari Kerajaan Sriwijaya, yaitu Prasasti Kedukan Bukit. M.Batenburg menemukannya di tepi Sungai Batang Hari yang mengalir ke Sungai Musi. Sejarah Prasasti Kedukan Bukit berasal dari tahun 604 Saka atau 682 M pada abad ke 7. Hasil bukti-bukti prasasti tersebut menjadi dasar tradisi penulisan di Indonesia. (Andhifani, 2013:2)

Belakangan ini, tradisi menulis berkembang pesat dengan penemuan berbagai bentuk peninggalan budaya termasuk manuskrip. Membuktikan hal ini, antara lain Arab (Arab Melayu/Jawi), Jawa (Hanacaraka), KaGaNga (Ulu) adapun beberapa jenis huruf lainnya seperti Rencong/Incung/Had/ Rejang/Serawai, dan Latin serta ada juga huruf Pallawa pada Prasasti Sriwijaya. (Andhifani, 2012:2)

Naskah kuno Sumatera Selatan terdiri dari berbagai macam aksara, seperti aksara Arab Melayu dalam bahasa Melayu, aksara Arab dalam bahasa Arab, aksara Jawa dalam bahasa Jawa (khususnya Jawa Tengah), kemudian sebagian berasal dari daratan Ulu yang merupakan aksara Ka-Ga-Nga atau huruf Ulu, disetiap daerah menyebutnya dengan huruf Komering, huruf Ogan, huruf Rejang, huruf Pasemah, dan sebaginya. Surat serupa juga ditemukan di Bengkulu, Jambi, dan Lampung. Aksara KaGaNga secara administratif termasuk di Provinsi Lampung, Jambi, Bengkulu dan Sumatera Selatan yang sampai batas waktu tertentu menunjukkan adanya perbedaan dari jenis aksara yang ada di daerah tersebut. Hal ini adanya struktur kemiripan dan urutan dalam bentuk penyusunan aksara pada manuskrip. (Andhifani, 2010:41)

Naskah Ulu banyak ditemukan di daerah perdalaman Sumatera, daerah tersebut terletak di daerah dataran tinggi atau pegunungan. Namun hasil dilapangan beberapa prasasti dan naskah susah atau sulit dilacak keberadaannya karena banyak faktor yang menyebabkan keberadaan prasasti dan naskah tidak berada di tempatnya lagi. Macam-macam naskah dan prasasti aksara di Sumatera yaitu : Tanduk berjenis kerbau dan kambing, Bambu, Kulit Kayu (Kaghas), Rotan, Batu, Daluang (Kulit Pohon yang bisa dilipat-lipat). Media tanduk berisi piagam atau pengumuman hari besar di suatu wiliayah. Media bambu berisi tetang ajaran agama Islam. Media rotan berisi keseharian atau karma. Media kulit kayu berisi pengobatan, mantra, yang sulit dimengerti. Media batu berisi pembelajaran dalam penulisan aksara Ulu. Sedangkan media daluang berisi doa-doa sehari-hari agar terhindar dari malapetaka. (Andhifani, 2017:175)

Keberadaan naskah tersebut masih banyak tersebar di kalangan masyarakat. Salah satu tempat penyimpanan naskah-naskah kuno adalah Perpustakaan Nasional Republik Indonesia (PNRI) sebagai Lembaga Pemerintah Non Kementrian. (Setyanto, 2018:7) Perpustakaan Nasional Republik Indonesia (PNRI) mempunyai koleksi lebih dari 10.000 naskah-naskah nusantara, naskah tersebut tercatat di dalam buku Katalog Induk Naskah-Naskah Nusantara (KINN) Perpustakaan Nasional Republik Indonesia Jilid 4 yang diterbitkan Yayasan Obor Indonesia tahun 1998.

Adapun naskah yang khendak diteliti oleh penulis ialah naskah berdialeg Melayu Sumatera Selatan di halaman 385 dengan nomor katalog Peti 91/E6. Naskah Peti 91/E6 merupakan aksara Renong/Ulu media tulisanya menggunakan bilah bambu atau dikenal gelumpai, berjumlah 20 bilah bambu, dan teknik penulisannya menggunakan teknik gores. Naskah ini mengandung syair Alegoris tentang Kumbang yang mencari kuntum Bunga yang berisi tentang suatu hukum perkara syarat dalam mencari jodoh. Menariknya dalam naskah ini terdapat nama pengarangnya yaitu Dapati makambang tiyang angkaya. Berdasarkan latar belakang masalah diatas maka penulis tertarik untuk mengkaji Naskah Aksara Ulu dalam Koleksi PNRI Peti No.91/E6. Adapun rumusan masalah yaitu : Bagaimna mengetahui inventarisasi, deksripsi, dan suntingan pada Naskah Koleksi Peti 91/E6 dan kandungan dari isi Naskah Ulu Koleksi Peti 91/E6. Dalam mengkaji naskah perlu menggunakan ilmu filologi. Adapun tujuan dalam penulisan ini, yaitu 
dapat memberikan informasi warisan budaya lokal dan memperlajari sejarah dari kemajuan kehidupan manusia dimasa lampau.

\section{B. TINJAUAN PUSTAKA}

Tinjauan pustaka merupakan uraian yang berfungsi menunjukkan penelitian atau karya-karya lain yang telah dahulu dikerjakan yang sesuai dengan penelitian agar tidak ada pengulangan duplikasi dengan penelitian yang telah ada sebelumnya. Disini penulis menemukan beberapa hasil penemuan sebelumnya yang terkait dengan penelitian yang akan dilakukan, diantaranya sebagai berikut :

Pertama, skripsi Nuzulur Ramadhona yang berjudul Suntingan Teks dan Analisis Isi Pada Naskah Ulu Sumatera Selatan Dalam Koleksi Peti PNRI No.91/3. Dalam skipsi ini membahas mengenai Perjalanan seorang pelaut Nusantara yang bernama Kudapariama, ia melakukan perjalanannya k beberapa negeri seperti Cina, Arab, Garis, dan Lebar Daun. Aliran sungai menjadi jalur perhubungan antara masyarakat ilir dan perdalaman (Uluan). Ide gagasan yang disampaikan oleh Bikubi Jangga dalam memberikan pendapatnya tentang suatu perkara mendapat pengaruh ajaran agama Islam. Sehingga agama Islam telah mempengaruhi dan menyebar kehidupan masyarakat di daerah uluan Sumatera Selatan.

Kedua, skripsi Masayu Naurotul Ulfah yang berjudul Naskah Gelumpai Pada Peti 91/E5 Di Perpusrakaan Nasional Republik Indonesia : Deskripsi Naskah, Suntingan Naskah, dan Analisis Isi. Dalam skripsi ini membahas tentang dialog antara guru dan murid atau kaum muda dan kaum tua. Dialog tersebut memiliki kisah yang mempunyai makna yang memberikan nilainilai keagamaan yang berisi ajaran untuk bertafakur, bersyahadat dan sholat lima waktu. Sehingga hal ini merupakan bukti bahwa pada masa itu naskah dijadikan sebagai media untuk berdakwah oleh para ulama dan masyarakat Sumatera Selatan.

Ketiga, skripsi M. Iksan yang berjudul Aspek-Aspek Ajaran Islam Dalam Naskah Gelumpai Beraksara Ulu Sumatera Selatan Koleksi PNRI Peti No.97/98 Suntingan Teks dan Analisis Isi. Dalam skripsi ini membahas dialog antara guru atau ulama dan murid, yang menyangkut ajaran agama yang berisi penciptaan alamsemesta, sifat dua puluh bagi Allah, dan tentang nyawa atau ruh dengan berbagai pengulangan. Dalam hal ini masyarakat masa lampau sudah mempunyai kehidupan sastra dipergunakan sebagai bagian dari usaha penyebaran agama Islam.

Keempat, hasil penelitian Wahyu Rizky Andhifani dalam Jurnal Siddhayatra yang berjudul Naskah Pusaka Raja Sulah Desa Siulak Mukai Kerinci Jambi. Dari hasil penelitiannya membahas naskah Incung koleksi Bapak Bacthiar Anif yang berkisah seorang pemuda yang bernama Kesumba yang sedang patah hati. Spesifik naskah tersebut berupa nyanyian yang bernafas kerinduan, berhiba hati, dan pengharapan. Bambu bertuliskan incung tersebut disebut sebagai buluh perindu.

Kelima, hasil penelitian Ahmad Rapanie Igama dalam buku yang berjudul Terjemahan : Gelumpai Tentang Nabi Muhammad Koleksi Museum Bala Putera Dewa (Naskah 07.17) yang diterbitkan oelh Pemprov Sumatera Selatan 2005. Dari hasil penelitiannya naskah gelumpai 14 bilah membahas tentang Nabi Muhammad. Namun perlu ditinjau serta menganalisis kembali dari segi tekstologinya.

Berdasarkan uraian tersebut maka penulis membahas secara spesifik dari hasil studi pustaka yang telah dilakukan oleh penulis, bahwasannya disini penulis mendapatkan persamaan dalam penilitian tersebut yaitu, membahas manuskrip berbahan media bambu/gelumpai/buluh. Kemudian perbedaannya dengan penelitian penulis ialah variasi bahasa dialek pada naskah serta kandungan isi naskah. Terlepas dari banyaknya karya yang telah membahas masalah naskah, maka penulis tertarik membahas mendalam dan lebih luas sebagaimana naskah Peti 91/E6 dapat 
memperkaya khazanah lokal dan menyumbang kebudayan yang unik, dan mendorong identitas dan jati diri bangsa tidak hanya tingkat lokal dan nasional tetapi menjadi budaya dunia.

\section{METODE PENELITIAN}

Metode penelitian suatu cara yang digunakan untuk memperoleh suatu tujuan yang didasarkan oleh sebuah fakta. Adapun jenis data yang digunakan pada penelitian ini adalah jenis data kualitatif, yaitu data-data tersebut didapatkan dari hasil pengamatan yang dilakukan dilapangan. Tujuan penelitian tergolong pada penelitian deskriptif dimana penelitian ini benar-benar memaparkan apa yang terdapat didalam naskah dari objek penelitian. (Daliman, 2002:7) Dalam menganalisis naskah penulis menerapkan metode penelitian filologi agar dapat mengetahui isi yang terdapat pada Naskah Ulu Peti 91/E6. Adapun langkah yang dilakukan sebagai berikut :

\section{a) Inventarisasi Naskah}

Inventarisasi naskah ialah sebagai upaya secermat-cermatnya dan semaksimal mungkin untuk menelusuri dan mencatat kebenaran naskah yang membuat salinan dari teks naskah yang akan dikaji oleh peneliti. (Lubis,1996:56)

\section{b) Deskripsi Naskah}

Deskripsi naskah yaitu melakukan identifikasi, baik terhadap kondisi fisik naskah, tulisan, dan isi teks maupun identitas pengarang dan penyalinan dengan tujuan agar menghasilkan sebuah deskripsi naskahdan teks yang lebih rinci dan jelas. (Fathurahman, 2015:75)

c) Penyalinan Naskah

Rangkaian yang dilewati oleh suatu teks yang turun-temurun disebut tradisi. Nakah yang diperbanyak karena orang ingin memiliki sendiri naskah tersebut, mungkin karena naskah asli sudah rusak dimakan zaman atau karena kekhawatiran terjadi suatu dengan naskah asli. Pada tahap inilah untuk memurnikan teks yang dibersihkan dari kesalahan dan dapat dipertangung jawabkan sebagai sumber kepentingan dalam bidang-bidang ilmu lain. (Baried, dkk, 1985:60)

\section{d) Suntingan Naskah}

Suntingan teks adalah penulisan ulang isi naskah dari dari proses alih aksara ke dalam alih bahasa sesuai dengan bacaan dan tulisan di dalam teks naskah atau isi naskah. Tujuannya ialah agar teks dapat dibaca oleh siapa saja yang berminat terhadap naskah tersebut, terutama dikalangan peneliti filologi. (Edwar Djamaris, 2002:19)

\section{e) Terjemahan}

Terjemahan adalah pemindahan bahasa dari bahasa sumber ke bahasa sasaran. Pemindahan Pemindahan bahasa tersebut harus terperinci dan lengkap. Hal ini bertujuan untuk memudahkan dalam memahami isi teks pada suatu naskah. Sehingga masyarakat yang tidak mengetahui bahasa aslinya, dapat menikmati, dan bahasa naskah tersebut lebih tersebar luas. (Darusuprapta, 1989:27)

\section{f) Analisis Isi}

Analisis isi adalah suatu penelitian untuk membuat infrensi-infrensi yang dapat ditiru dengan memperhatikan konteksnya. Analisis isi bertujuan untuk mengungkapkan pesan yang terkandung dalam teks naskah yang kemudian dijelaskan menurut pemahaman dan kemampuan yang dimiliki. Namun dalam hal ini penulis tidak banyak menterjemahkan secara terperinci karena peneliti kesulitan melakukan arti dari setiap makna kalimat pada naskah. Oleh karena itu, perlunya adanya kajian lebih lanjut dari aspek tekstologi.

\section{HASIL DAN PEMBAHASAN}




\section{a) Deskripsi Naskah}

Naskah Koleksi Perpustakaan Nasional Republik Indonesia Peti 91/E6 merupakan naskah yang tersimpan di lantai 9 yaitu Layanan Koleksi Naskah Nusantara dan tercatat di buku Katalog Induk Naskah-naskah Nusantara (KINN) Jilid 4 yang diterbitkan oleh Yayasan Obor Indonesia tahun 1998 di halaman 385 pada bagian Katalog Naskah Melayu. Dari inventarisasi yang telah dilakukan diatas, bahwasannya Naskah Peti 91/E6 merupakan naskah tunggal dalam sebuah bahan penelitian. Maka dari itu penulis memberikan informasi tersebut dengan tujuan mendapatkan data yang akurat serta sesuai pada wujud aslinya.

Berikut uraian deskripsi Naskah Ulu Koleksi PNRI Peti No.91/E. Judul Naskah: Tanpa Judul, Nomor Koleksi: 91/E6, Jumlah Teks: Satu, Jenis Naskah: Gelumpai, Bahasa: Melayu Daerah Sumatera Selatan, Bahan: Bambu, Teknis Tulis: Gores, Kondisi: Baik, Jumlah Halaman/Bilah: 20 Halaman/Bilah, Penjilidtan: Disatukan Menggunakan Benang.

Naskah Ulu Koleksi PNRI Peti 91/E6 menggunakan aksara Ulu, dengan panjang 22,5 cm dan lebar bilah $3,4 \mathrm{~cm}$. Jarak antar baris $0,5 \mathrm{~cm}$, Warna naskah Coklat dan warna tinta tulisan berwarna hitam. Penomoran naskah menggunakan aksara Ulu.

Kondisi naskah baik, lengkap, huruf jelas, tulisan terbaca namun pada bilah ke-4 dan bilah-9 terdapat kondisi yang kurang terlihat sehingga menutupi beberapa huruf. Pada bagian sudut naskah terdapat halaman penomoran naskah menggunkan huruf $\mathrm{Ka} \mathrm{Ga} \mathrm{Nga,} \mathrm{serta} \mathrm{ujung} \mathrm{sisinya}$ kiri terdapat lubang tempat tali yang berfungsi untuk menyatuhkan atau mengikat bilah perbilah menjadi satu naskah. Informasi lebih dari naskah ini terdapat nama pemilik naskah yaitu : Dapati makambang tiyang ngkaya. Kemudian adanya tanda pemula naskah pada bilah ke-1 dan bilah ke-20 yang melambangkan gambar matahari.

\section{b) Penyalinan Naskah}

Penyalinan naskah bertujuan untuk mempermudah pembaca melihat membaca dan memahami bentuk aksara,variasi,serta tanda yang terdapat pada naskah. Naskah Peti 91/E6 terdapat tulisan yang tidak terbaca pada bilah ke-4 dan bilah ke-9, sehingga diberi tanda (...) berikut gambar penyalinan naskah :

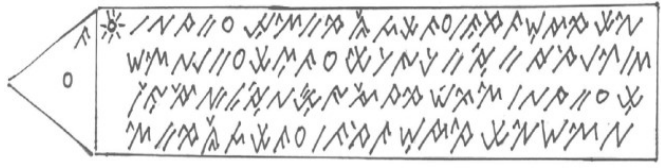

Gambar Bilah 1 Naskah Ulu Peti 91/E6

(Sumber : Nuzulur Ramadhona)

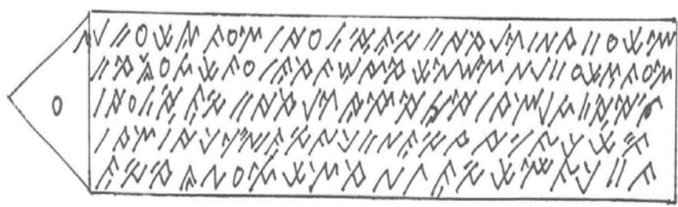

Gambar Bilah 2 Naskah Ulu Peti 91/E6

(Sumber : Nuzulur Ramadhona)

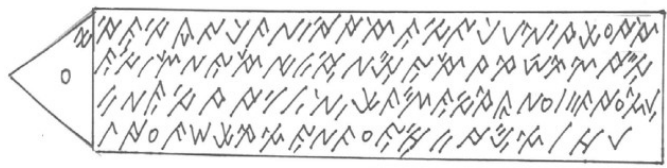

Gambar Bilah 3 Naskah Ulu Peti 91/E6

(Sumber : Nuzulur Ramadhona)

AิANWNWO \& WNAS, WWAWANMWOXN",

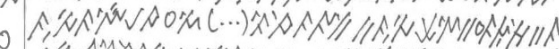

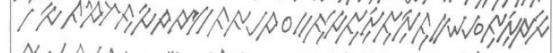

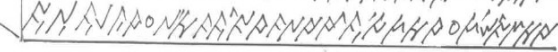

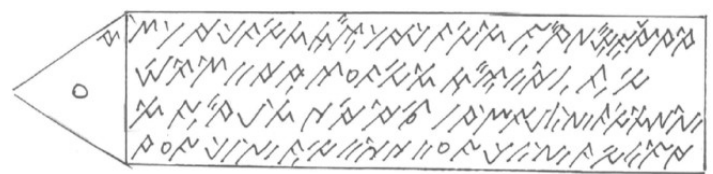

Gambar Bilah 11 Naskah Ulu Peti 91/E6

(Sumber : Nuzulur Ramadhona)

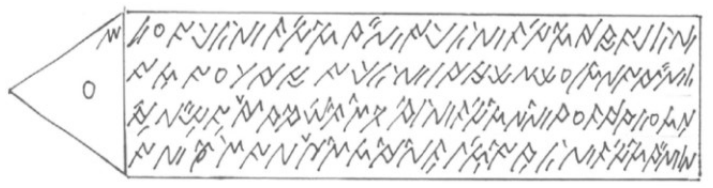

Gambar Bilah 12 Naskah Ulu Peti 91/E6

(Sumber : Nuzulur Ramadhona)

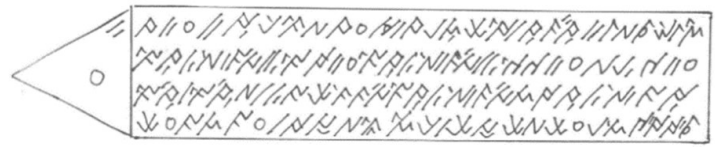

Gambar Bilah 13 Naskah Ulu Peti 91/E6

(Sumber : Nuzulur Ramadhona)

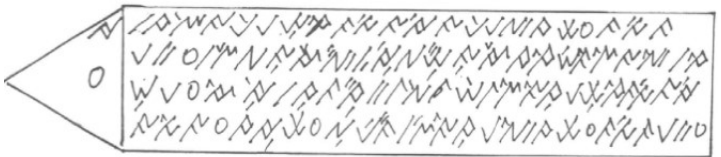


Gambar Bilah 4 Koleksi PNRI Peti 91/E6

(Sumber : Nuzulur Ramadhona)

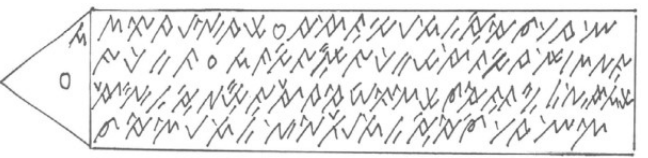

Gambar Bilah 5 Naskah Ulu Peti 91/E6

(Sumber : Nuzulur Ramadhona)

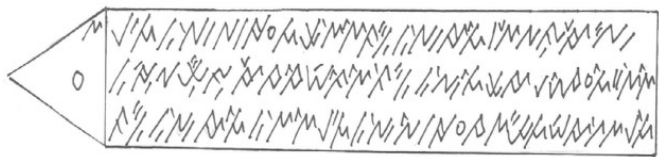

Gambar Bilah 6 Naskah Ulu Peti 91/E6

(Sumber : Nuzulur Ramadhona)

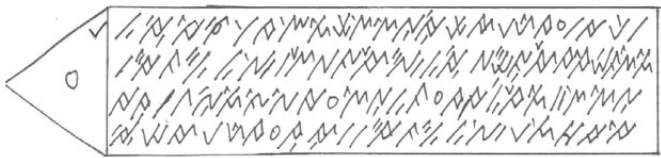

Gambar Bilah 7 naskah Ulu Peti 91/E6

(Sumber : Nuzulur Ramadhona)

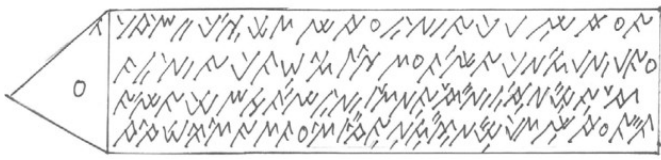

Gambar Bilah 8 Naskah Ulu Peti 91/E6

(Sumber : Nuzulur Ramadhona)

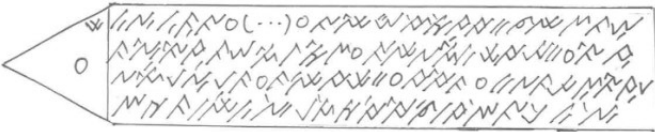

Gambar Bilah 9 Naskah Ulu Peti 91/E6

(Sumber : Nuzulur Ramadhona)

s

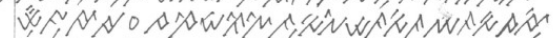

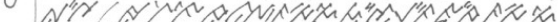

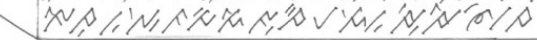

Gambar Bilah 10 Naskah Ulu Peti 91/E6

(Sumber : Nuzulur Ramadhona)
Gambar Bilah 14 Naskah Ulu Peti 91/E6

(Sumber : Nuzulur Ramadhona)

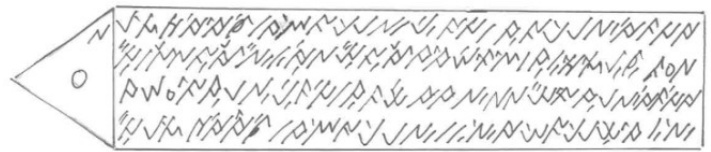

Gambar Bilah 15 Naskah Ulu Peti 91/E6

(Sumber : Nuzulur Ramadhona)

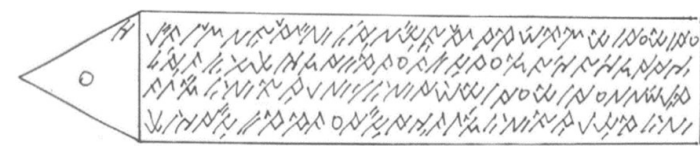

Gambar Bilah 16 Naskah Ulu Peti 91/E6

(Sumber Nuzulur Ramadhona)

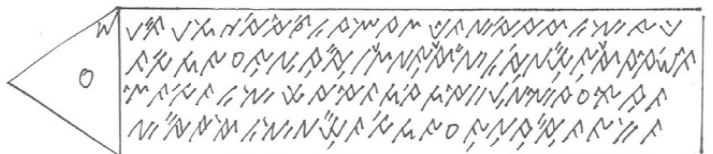

Gambar Bilah 17 Naskah Ulu Peti 91/E6

(Sumber : Nuzulur Ramadhona)

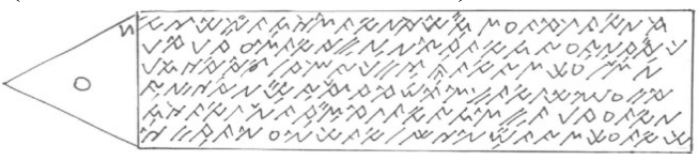

Gambar Bilah 18 Naskah Ulu Peti 91/E6

(Sumber : Nuzulur Ramadhona)

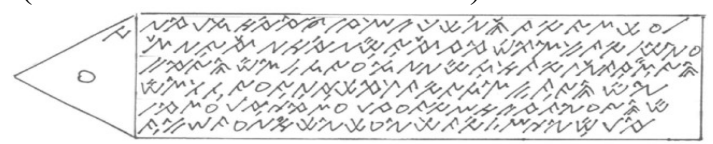

Gambar Bilah 19 Naskah Ulu Peti 91/E6

(Sumber : Nuzulur Ramadhona)

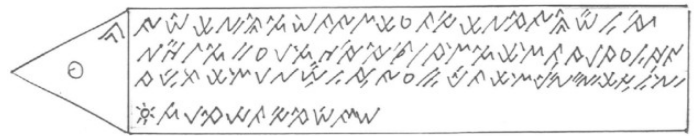

Gambar Bilah 20 Naskah Ulu Peti 91/E6

(Sumber : Nuzulur Ramadhona)

\section{c) Suntingan Teks}

Berikut penyuntingan naskah yang disandingkan dengan hasil transliterasi pada Naskah Aksara Ulu Koleksi PNRI Peti 91/E6:

\section{Bilah 1 (Ka)}

Balatas munyisatinggar damak bekute kayu jati maliya nilapas manuk mibeape sarung serate pagi banabar ujar ngaburung lamun ajar tatiyang kini balatas muni satinggar damak bekute kayu jati maliya

\section{Bilah 2 (Ga)}

nilapas manuk nibar burung kumbang serate pagar

belatas munyi satinggar damak bekute kayu jati maliya nilapas manuk nibar burung kumbang serate pagi tu jiri wuri betanye pade burung rincang batanye berape bilangan kumbang ape sala kumbang terabang ape makan kumbang tinggal dimane talaga kumbang mandi 


\section{Bilah 3 (Nga)}

ape sakarang kumbang

ngape kaarang raje kumbang

ape pangitam raje kumbang

banarla ujarngan burung lamun ujar tatiyang

kini

rambun sala kumbang tarabang b la

makan kumbang tinggal di besakar di pugar

kayu mati

di ulak uwung sarupun dibawa

\section{Bilah 4 (Ta)}

pakara malay sane telaga kumbang mandi anam bilangan kumbang kanyin pat di (.....)

kite ke ase sekumbang manis

ka duwe saku pandang

ka tige kumbang tarase

$k a$ apat sekumbang ulung-ulung ku sayap, ulung rambang, ulung ku pagut lawang ka ku

itu kala raja kumbang dawat dayang inawarana

\section{Bilah 5 (Da)}

itu pangitam raje kumbang

pade burung rincang batanye

ape sak da kumbang andun

ape samanje kumbang tande

banar la ujarngan burung lamun ujar tatiyang

kini

mencari kukasun bunge

jadi mancari pade ni pade bunga libar

pade burung rincang betanye

\section{Bilah 6 (Na)}

dimane ni padang bunge libar

dimane ni kabun bunge

jadi benar la ujar ngan burung lamun ujar tatiyang kini

kebun bunge di majapayit disane ni kebun bunge

jadi disane ni padang bunge libar tanaman dayang jagani

\section{Bilah 7 (Pa)}

pade burung rincang betanye

dimane ni lurung majapahit

berape babaran kabun bunge

banar la ujar ngan burung lamun ujar

tatiyang kini

di ratu bagalung di ilir lubuk tara butar

disane ni lurung majapahit tuju babaran kabun bunge

pade warang rincang betanye

\section{Bilah 8 (Ba)}

sape wung manandar bunge

ape penandur a kabunge

ape kayu di gawin kandang

ape lading di pengapak kandang

ape penyawa kandang bunge

benar la ujar ngan burung lamun ujar tatiyang

kini

anak ni batin ulu dusun

lamun penandur akan

\section{Bilah 9 (Ma)}

bunge bukuk (..........) andian jewe tarasa

ncandana kayu kaling itu kayu di gawin

kandang

lading sama rames itu lading pengapak

kandang

rames tarik selakam nur itu panyawa kabun di bunge

pade warang rincang bertanye

ape bunge kembang dusun

\section{Bilah 10 (Ca)}

ape bunge kembang di itu

banar la ujar ngan burung lamun ujar tatiyang kini

kembang lima kembang kalapa

kembang tanjung luwan baru ge itu

bunge kembang di dusun

pakan utan kembang di utan

pada burung rincang betanye

\section{Bilah 11(Ja)}

berape kembang didusun

berape kembang di utan

lamun ujar tatiyang kini

saratus kembang di dusun

saribu kembang di utan

pade warang rincang betanye

ape bunge kembang di langit

ape bunge kembang di sawiwas

ape bunge kembang sairas

\section{Bilah 12 (Nya)}

ape bunge kembang di tangan

ape bunge kembang di ratu

ape bunge kadua a barambaw

ape bunge barambaw malam

banar la ujar ngan burung lamun ujar tatiyang kini

batang bunge kembang di langit karatas daluang cine kaluwar ni dari liku gadung itu bunge kembang di tangan 


\section{Bilah 13 (Sa)}

balatas sarupe kilat basi tapadu mari

batu katun sagale ncaye gani

itu bunge kembang sairas itu bunge kembang sairas

itu bunge kembang sawiwas lapuas itung baitung la babua make kembang

itu bunge kembang di ratu

bunge arum ada barambaw rangge

di pe barambau malam

pade warang rincang betanye

\section{Bilah 14 (Ra)}

ape pamutih kembang arang

ape pangitam kembang kapas

banar la ujar ngan burung lamun ujar tatiyang kini

angin batiyup jiro batu katun segale ncaye gani itu pamutih kembang arang ambia tarum lupangkan banang itu pangitam kembang kapas

\section{Bilah 15 (La)}

pade warang rincang batanye

ape pangapung kambang batu

ape pangarang kambang rambun

banar la ujar ngan burung lamun ujar tatiyang kini

batu buwi di puncuk latay itu pangapung

kambang batu

kambang ba ta nga la laman itu pangarang

kambang rambun

pade warang rincang betanye

ape pangabang bunge raye

ape pamutih bunge pakan

\section{Bilah 16 (Wa)}

banar la ujar ngan burung lamun ujar tatiyang kini

mibar mibar burung kasumbe mabawe darah satik kasambut di awang-awang dara rawu kagading bunge itu pengabang bunge raye mibar mibar lalayang putih membawe rambun satitik rambun rawu kagading bunge itu pemutih bunge pakan

Bilah 17 (Ya)

pade warang rincang betanye tana mpakangarang raje bunge ape kembang da a ulu turun

banar la ujar ngan burung lamun ujar tatiyang kini

kumbang ku bunge marari ku datang dari sapu langit itu kangaran raje bunge lamun kambang da ulu turu

\section{Bilah 18 (Ha)}

kease kambang samilon

kuduwe ni kembang late midun n

katige kembang ladi pati

pat ni kembang rasulu la itu kembang da a ulu turun

pade warang rincang betanye

ape sasunggu kembang anam

banarla ujarnga warang lamun ujar tatiyang

kini

sekembang gamilip malati sari

duwe kembang gelar katunun

tiga kembang ada ni suku

pat kembang lawi satu kali

lime kembang benda wali yun

$k a$ anam kembang melati

\section{Bilah 19 (Mba)}

pade warang rincang batanye

sape malanggar kembang anam

banar la ujar la warang lamun ujar tatiyang

kini

sakembang bemili sari anggiyan ni bu dua di lalaman

duwe kembang galar katunun anggiyan $n i$ bubua ulu ruma

tige kembang ada ni suku amggiyan li betina paruwatin

pat kembang nyawa satu kali anggiyan kusiyak lawan malim

lime kembang benyawa liyun pariayi manganggi diye

\section{Bilah 20 (Ngga)}

$k a$ anam kembang malati anggiyan ni bujang

lawan gadis

pade warang rincang betanye

dimane kutapat burua tipung

kemane palayun burua sumpang

kemane mpalangan mambw bunge

Dapati makambang tiyang ngkaya 


\section{d) Terjemahan Teks}

Proses setelah dari tranliterasi naskah ialah terjemah, terjemah dilakukan dengan baris perbaris, berikut terjemahan pada Naskah Aksara Ulu Koleksi PNRI Peti 91/E6 :

\section{Bilah 1 (Ka) \\ batas suara sampai ke demak yang merupakan kota kayu jati merah melepas burung dari sarang pada suatu pagi benarla kata burung, namun tunggulah disini batas suara sampai ke demak yang merupakan kota kayu jati merah}

Bilah 2 (Ga)

melepas burung kumbang (hitam) beserta sangkar

batas suara sampai ke demak yang merupakan kota kayu jati merah

melepas burung kumbang (hitam) disuatu pagi sambil ia bertanya pada burung kembali bertanya

berapa banyakjumlah kumbang

apa salah kumbang terbang

apa makanan kumbang

dimanakah telaga tempat kumbang mandi

\section{Bilah 3 (Nga)}

apakah sekarang kumbang

telah menjadi raja kumbang

apa yang menghitamkan raja kumbang

benar apa kata burung namun tunggulah disini

ke rimba (hutan) salah kumbang terbang belum makanan

kumbang tinggal bersarang pada kayu jati

diatas pohon dibawah ada perangkap

\section{Bilah 4 (Ta)}

perkara sekarang tempat kumbang mandi enam bilangan kumbang minyak di (....)

kita serasa kumbang yang manis

berdua saling tatap

ketiga kumbang terasa

ke empat satu kumbang ungulan-unggulan sayap unggul, yang paling kuat kupatuk sama kuku

dengan itu kalah lah raja kumbang

Bilah 5 (Da)

itu pangitam raja kumbang

pada burung bertanya

apakah ada kumbang menantang

apa semenjak kumbang bertanda benarla kata burung namun tunggulah disini

mencari kuntum bunga

jadi mencari pada bunga besar

pada burung bertanya

\section{Bilah 6 (Na)}

dimana hamparan bunga yang luas (besar)

dimana ini kebun bunga

jadi benarla kata burung, namun kata burungnya kini

kebun bunga di majapahit disana kebun bunga

jadi disana ini hamparan bunga luas tempat para dayang

\section{Bilah 7 (Pa)}

pada burung bertanya

dimana tempat majapahit

berapa banyak kebun bunga

benarla kata burung namun kata burungnya kini

di ratu bergulung di ilir tampungan air tara buntar

disana jalan majapahit banyak tuju kebun bunga

pada orang ia bertanya

\section{Bilah 8 (Ba)}

siapa orang pemetik bunga

apakah sang penanam bunga

apakah kayu dibikin kandang

apakah pisau dijadikan pemotong kandang

apakah dijadikan sawah yang banyak bunga

benarla kata burung namun katanya tunggu

disni

anak yang sudah di ulu desa

namun penanam akan

\section{Bilah 9 (Ma)}

bunga yang keras (.....) akan menjadi jiwa yang terasa cendana kayu hitam itu kayu dibikin kandang pisau sama tajam itu pisau pemotong kandang semu kan tertarik seperti cahaya yang akan mencapai inti bunga (sari bunga)

pada orang ia bertanya apakah bunga mekar di desa

Bilah 10 (Ca)

apa bunga akan mekar disana 
benarla kata burung, namun tunggulah disini bunga lima bunga kelapa bunga tanjung itu bunga besar baru itu bunga mekar di desa makan di hutan kumbang di hutan pada burung kembali bertanya

\section{Bilah 11(Ja)}

berapa mekar di desa berapa mekar di hutan namun dia bertanya lagi seratus bunga mekar di desa seribu bunga mekar di hutan pada orang kembali bertanya apakah bunga mekar di langit apa bunga mekar tidak tertata/tersusun apa bunga mekar tertata

\section{Bilah 12 (Nya)}

apa bunga mekar ditangan

apa bunga mekar di ratu

apa bunga kedua menumbulkan harum

apa bunga berbau malam

benarla apa yang dikatan burung namun tunggulah kini

batang bunga mekar dilangit kertas daluang cina keluar dari belokkan tanaman itu bunga mekar ditangan

\section{Bilah 13 (Sa)}

batas serupa (seperti) kilat tersusun batu segala cahaya api

itu bunga mekar tidak tertata itu bunga mekar tidak tertata

itu bunga mekar tertata sudah puas berhitung maka bunga itu bunga mekar di ratu

bunga harum ada berbau raja

di bau malam

pada orang ia kembali bertanya

\section{Bilah 14 (Ra)}

apa yang memutihkan kumbang (hitam)

apakah penghitam kumbang kapas

benarla kata burung namun katanya tunggu kini

angin ber tiup batu kelihatan segala cahaya itu memutihkan kumbang (hitam)

ambil duri pasangkan benang itu penghitam kumbang kapas

Bilah 15 (La)

pada orang bertanya kembali apa yang bisa membuat kambang batu terapung

apa yang menjdi tujuan rombongan rimba

benarla kabar burung namun katanya tunggu

kini

batu buwi diatas (loteng) itu tempat kambang batu terapung

rombongan di halaman itu rangkaian rombongan rimba

pada besan kembali bertanya

apa pemerah bunga raya (bunga sepatu)

apa pemutih bunga yang bisa dimakan

\section{Bilah 16 (Wa)}

benarla kata burung katanya tunggu kini

terbang terbang pewarna membawa darah sampai kelangit

dari warna kuning gading bunga itu bewarna bunga raya (bunga sepatu)

terbang layang putih membawa sesuatu dari hutan sedikit sampai ke pantai gading bunga itu bunga pemutih makan

Benarlah kata burung, namun katanya sabar

\section{Bilah 17 (Ya)}

pada orang kembali bertanya

di perkarangan tanah raja bunga itu mekar lalu runtuh

benarlah kata burung namun tunggulah kini

kumbangku bunga bejajar mendatangi dari sapu langit hingga ke rumah raja bunga

namun mekar lalu runtuh

\section{Bilah 18 (Ha)}

kesatu bunga

kedua bunga mendatar

ketiga bunga jadi air pati (air sari)

ke empat bunga rasulullah itu bunga dahulu turun

kepada orang kembali bertanya

apa sesungguhnya dalam enam bunga

benarla kata besan namun tunggu kini

satu warna gamerlap sari bunga melati

dua bunga terpetik

tiga bunga disiku tangan

empat bunga diambil satu kali

lima bunga benda para wali

ke enam bunga melati

Bilah 19 (Mba)

pada orang kembali bertanya

siapa melanggar ke enam bunga

benarla kata besan namun tunggulah kini 
Tanjak: Jurnal Sejarah dan Peradaban Islam, Vol. I No. 2, 2021

satu bunga memiliki sari yang tumbuh dua di halaman

dua bunga terpetik bakal diambil syarat ulu rumah

tiga bunga ada di siku tangan perempuan berumur

empat bunga bernyawa satu kali diambil untuk

menghadap guru

lima bunga bernyawa dengan jiwa para priayi untuk diambil
Bilah 20 (Ngga)

ke enam bunga melati diambil untuk bujang

berhadapan dengan gadis

pada orang kembali bertanya

dimana tempat aku menemukan orang pintar

kemana aku harus berserah

kemana aku menyerahkan bunga

Dapati makambang tiyang ngkaya

\section{e) Analisis Teks}

Dalam menganalisis teks Naskah Ulu Peti 91/E6 ini, penulis mengelompokkan lima pembahasan dari dua puluh bilah agar mempermudah pembaca dari makna yang terkandung dalam isi teks pada naskah tersebut, yaitu :

Bagian pertama, ada bilah ke-1, menjelaskan cerita ini terkenal sampai pada kerajaan Demak. Bergeraklah burung mengawali aktivitasnya pada waktu pagi dari sarangnya, terbanglah burung tersebut dari tempat tinggalnya. Pada bilah ke-2, terdapat dialog burung dengan burung yang sedang melakukan aktivitas pada pagi hari, membicarakan seorang tokoh yang bernama Kumbang. Kemudian pada bilah ke-3, menjelaskan bagaimana kabarnya Kumbang apakah ia telah menjadi seorang Raja serta keberadaannya dan telaga tempat mandi Kumbang tersebut. Pada bilah ke-4 menjelaskan hukum perkara telaga tempat Kumbang mandi.

Bagian kedua, bilah ke-5 dan bilah ke- 6 terdapat dialog antara burung dengan burung yang menjelaskan bahwa Kumbang sedang mencari kuntum Bunga, kemudian pada bilah ke-6 menjelaskan tempat kebun Bunga yang berada di Majapahit. Pada bilah ke-7 menjelaskan alamat lengkap menuju jalan Majapahit yaitu di Ratu Bergulung di Ilir Tampungan Air Tara Buntar?.

Pada bagian ketiga, bilah ke-8 terdapat dialog antar burung yang menjelaskan bahwa, Kumbang mengirim utusan untuk yang mencari informasi tentang Bunga tersebut yang sudah pindah dan tinggal di Ulu desa. Pada bilah ke-9 menjelaskan tentang bagaimana kondisi keberadaan Bunga tersebut. Kemudian pada bilah ke-10 menjelaskan tentang burung yang memberikan informasi lima Bunga Kelapa dan Bunga Tanjung syarat jika ingin pergi ke daerah Ulu.

Kemudian pada bagian keempat, bilah ke-11, menjelaskan tentang perkembangan Bunga yang berkembang di Desa dan di Hutan pada kawasan Uluan. Pada bilah ke-12, terdapat kata Kertas Daluang Cina. Pada bilah ke-13, menjelaskan kondisi dan keberadaan Bunga bahwa Bunga yang banyak ada pada Ratu dan Bunga yang harum ada pada Raja. Pada bilah ke-14 menjelaskan tentang Kumbang Hitam? dan Kumbang Kapas? bilah ke-15 terdapat kata Bunga Raya/Bunga Sepatu.

Terakhir yaitu bagian ke lima, bilah ke-16, bilah ke-17, bilah ke-18, bilah ke-19, dan bilah ke-20. Dapat disimpulkan dalam naskah Peti 91/E6 bahwa terdapat dialog antara utusan Raja Kumbang dengan penduduk setempat. Pada bilah ke-18 terdapat kata Bunga Melati yang menjelaskan tentang hukum adat mengenai pemilihan gadis atau pasangan seperti syarat mencari jodoh. Kemudian pada bilah ke-19 menjelaskan bagaimana jika melanggar hukum adat dalam mencari jodoh tersebut. Bilah ke-18 dan ke-19 terdapat kata Rasulullah dan Priayi yang membuktikan bahwa secara tidak langsung sebagian masyarakat Ulu sudah memeluk agama Islam. Kemudian bilah ke-20 terdapat nama penulis naskah Dapati makambang tiyang ngkaya yang menunjukkan bahwa mempunyai kedudukan yang unggul dan terhormat sekaligus mahir pada penulisan Ka-Ga-Nga yang berlaku pada zamannya. 


\section{E. KESIMPULAN}

Setelah penulis melakukan penelitian terhadap naskah pada Peti 91/E6 tersebut, naskah ini menceritakan kisah Kumbang yang mencari kuntum Bunga. Kumbangpun memanggil utusannya untuk mencari keberadaan Bunga namun Bunga tersebut berasal dari Majapahit yang tinggal di Ilir keberadaan Bunga saat ini sudah tinggal di Ulu desa dan Syarat untuk pergi ke Uluan membawa Lima Bunga Kelapa dan Bunga Tanjung. Utusan Kumbang melanjutkan perjalanan mencari Bunga baik di Desa maupun di Hutan bagian wilayah Ulu, kemudian Bunga yang banyak ada pada Ratu dan Bunga yang harum ada pada Raja. Berbagai jenis Bunga seperti Bunga Sepatu dan Bunga Melati. Utusan Kumbang tersebut diberikan suatu hukum perkara tentang syarat mencari jodoh.

Naskah ini menyampaikan hukum perkara mencari jodoh melalui perantara Rasulullah dan Priayi yang mempunyai makna pada nilai keagamaan. Kemudian dijadikan sebagai media berdakwah sejak berakhirnya kerajaan Majapahit hingga berdirinya kerajaan Demak, sehingga

tersebar luas sebelum masa Kesultanan Palembang Darussalam. Kelemahan penulis belum dapat mengungkapkan secara terperinci maksud teks dalam tiap bilah perbiah pada naskah ini. Hal itu disebabkan banyak kata-kata yang sulit dipahami untuk memperoleh arti dari setiap kalimat tersebut. Oleh karena itu, teks ini memerlukan pengkajian lebih jauh dari segi aspek tekstologi dalam penelitian selanjutnya.

\section{DAFTAR PUSTAKA}

Ahmad Rapanie, dkk. 2005. Gelumpai Tentang Nabi Muhammad. Palembang : Diknas Museum Negeri Sumatera Selatan.

Darusuprapta. 1984. Arti dan Nilai Babad dalam Kebudayaan Jawa. Yogyakarta : Proyek Javanologi.

Edwar Djamis. 2002. Metode Penelitian Filologi. Jakarta : Manaco.

Lubis Nabilah. 1996. Naskah, Teks, dan Metode Filologi. Jakarta : Forum Kajian Bahasa dan Sastra Arab Fakultas Adab IAIN Syarif Hidayatullah.

Masayu Naurotul Ulfah. 2018. Naskah Gelumpai Peti 91 Di Perpustakaan Nasional Republik Indonesia : Deskripsi Naskah, Suntingan Teks, dan Analisis Isi. Palembang : Fakultas Adab dan Humaniora.

M. Iksan. 2020. Aspek-Aspek Ajaran Islam Dalam Naskah Gelumpai Beraksara Ulu Sumatera Selatan Koleksi PNRI Peti No.97/98 Suntingan Teks dan Analisis Isi. Palembang : Fakultas Adab dan Humaniora.

Nuzulur Rahmadhona. 2018. Suntingan dan Analisis Isi Teks pada Naskah Ulu Sumatera Selatan dalam Koleksi Peti PNRI No.91/3+. Palembang: Fakultas Adab dan Humaniora.

Oman Fathurahman. 2015. Filologi Indonesia Teori dan Metode. Jakarta : Pranada Media.

Siti Baroroh Baried, dkk. 1985. Pengantar Teori Filologi. Yogyakarta : Badan Penelitian dan Publikasi Fakultas.

Wahyu Rizky Andhifani. 2010. Naskah Ulu/Naskah KaGaNga di Desa Bumi Ayu. Jurnal Siddhayarta. Vol.15, No.1.

Wahyu Rizky Andhifani. 2012. Naskah Kuna Pusaka Raja Sulah Desa Siulak Mukai Kerinci Jambi. Jurnal Siddhayarta. Vol.17. No.2.

Wahyu Rizky Andhifani. 2013. Laporan Arkeologi Survei Aksara dan Naskah KaGaNga Provinsi Bengkulu. Palembang : Balai Arkeologi.

Wahyu Rizky Andhifani. 2017. Naskah dan Prasasti Beraksara Ulu. Buku Retrospeksi 25TH Balai Arkeologi Sumatera Selatan. Palembang : Balai Arkeologi. 